\title{
O TRABALHO DOCENTE NO MAGISTÉRIO SUPERIOR EM TEMPOS DE CRISE E DE RECONFIGURAÇÃO
}

\section{TEACHING WORK IN HIGHER EDUCATION IN TIMES OF CRISIS AND RECONFIGURATION}

\author{
Suelaynne Lima da Paz \\ Doutora em Educação. Professora da Universidade Estadual de Goiás, Goiânia, GO - Brasil \\ suepaz@gmail.com
}

João Ferreira de Oliveira

Doutor em Educação. Professor do Programa de Pós-Graduaçâo em Educaçáo da Universidade Federal de Goiás, Goiânia, GO - Brasil. joao.jferreira@gmail.com

\begin{abstract}
Resumo: $\mathrm{O}$ trabalho analisa os processos de intensificação e de precarização do trabalho docente que vem se concretizando no campo universitário, tendo a Universidade Federal Goiás (UFG) como objeto de estudo. Objetiva-se discutir os embates do trabalho docente frente ás políticas públicas de educaçáo superior a partir de 1990, especificamente as políticas de expansão e de regulação do trabalho docente no magistério superior. Foram realizadas pesquisas bibliográfica, documental e empírica, sendo esta última efetivada por meio de entrevistas com gestores acadêmicos e pesquisadores de programas de pósgraduação stricto sensu de diferentes áreas de conhecimento da UFG. A pesquisa evidencia, dentre outros aspectos, que os processos de flexibilizaçáo, intensificação e precarização estão presentes na produção do trabalho acadêmico da instituição, corroborando certo alinhamento às demandas econômico-produtivas. $\mathrm{O}$ fato inexorável é que estáo ocorrendo alteraçôes na natureza e no caráter do trabalho docente, decorrentes, em grande parte, de demandas externas, o que tem ampliado a heteronomia na produçáo, organizaçáo, gestáo e finalidades da universidade.
\end{abstract}

Palavras-chave: Magistério Superior. Políticas de Educaçáo Superior. Trabalho Docente.

Aвstract: The present work analyses the processes of intensification and precariousness on teaching work that has been taking place in the university field, with the Federal University of Goias (UFG) as the object of study. The goal is to discuss the clashes of teaching work front of public policy on higher education from I990, specifically the policies of expansion and regulation of teaching work in higher education. As methodology, we realized a bibliographical, documentary and empiric research, being 
the latter effected by the means of interviews with academic managers and researchers of strictosensu graduation programs of different knowledge areas of UFG. Among other aspects, the research highlights that the processes of flexibilization, intensification and precariousness are present in the production of academic work from the institution, supporting certain alignment to the economic-productive demands. The inexorable fact is that there has been occurring alterations on the nature and character of teaching work, which are largely due to external demands, that has been amplifying the heteronomy on production, organization, management and purposes of the University.

Keywords: University Teaching. Policies Of Higher Education.Teaching Work.

\section{Introdução}

Para se compreender as bases do magistério superior na atualidade faz-se necessário considerar a estreita relação da educação com os processos sociais mais amplos de produção e reprodução da sociedade capitalista. Nessa direção, cumpre contextualizá-la no cenário social e histórico de reestruturaçáo produtiva do capitalismo, tendo por base as transformaçôes iniciadas nos grandes centros de poder econômico e político global a partir do final dos anos de 1970. No Brasil, esse processo, alinhado ao programa neoliberal do Consenso de Washington, chegou por volta dos anos de 1990, com uma ampla reforma do Estado. Pode-se dizer que o neoliberalismo é uma doutrina que exerce o papel de sustentação ideológica da reestruturaçáo produtiva ou da chamada acumulação flexível, defendendo a absoluta liberdade do mercado. Para Boito Júnior (1999), a ideologia neoliberal estrutura-se no livre comércio, que assume o papel de mediador do capital e de novas conjecturas societais. Nessa conjuntura, a busca por novos nichos de acumulação do capital tem o conhecimento como base para a produção de novas tecnologias e inovaçóes, o que passou a implicar políticas, programas e açóes que buscam ajustar e subordinar o campo científico e educacional, sobretudo a educaçáo superior, ao campo econômico. Nesse contexto, ciência e educaçâo passam a ser cada vez mais vistas como mercadorias, serviços ou meios para ampliar a competitividade das empresas no contexto da chamada economia do conhecimento. Como afirma Harvey (2012, p. I5I),

o próprio saber se torna uma mercadoria-chave a ser produzida e vendida a quem pagar mais, sob condiçôes que são elas 
mesmas cada vez mais organizadas em bases competitivas [...]. A produção organizada de conhecimento passou por notável expansão nas últimas décadas, ao mesmo tempo que assumiu cada vez mais um cunho comercial (como o provam as incômodas transiçôes de muitos sistemas universitários do mundo capitalista avançado de guardiōes do conhecimento e de sabedoria para produtores subordinados de conhecimento a soldo do capital corporativo).

Destacam-se, no âmbito educacional, os desdobramentos da reestruturação produtiva pelo menos em duas perspectivas: a) na abordagem da educação como serviço, e não como direito social e humano, o que a torna produto comercializável, mercadoria, que amplia os lucros do capitalismo; b) na mudança no fundamento do trabalho docente de formação do aluno como cidadão político, para uma ideia de formação para competências individuais e profissionalizantes. Essas mudanças ganham forma e força pelo campo das políticas públicas educacionais, que buscam moldar o trabalho docente para atender às novas exigências e demandas formativas do capitalismo globalizado. Para tanto, a incorporação de concepçóes vinculadas à lógica da meritocracia constitui estratégia de controle e adequação à fase de acumulação flexível do capital. (MANCEBO; MAUÉS; CHAVES, 2006)

As alterações no processo de produção e de acumulação do capital implicam mudanças no trabalho e nos processos de formação e geração de conhecimento novo, o que tem impactado fortemente as universidades. Além de atingir diretamente as mais diversas profissóes, resultando em perda de autonomia e aumento da precarização das condiçôes de trabalho, observam-se mudanças nos mecanismos e processos de produção e gestão, especialmente no campo universitário, produzindo uma forte intensificação do trabalho em decorrência dos novos modos de avaliação da produçáo científica, que privilegiam mais o número de artigos, o registro de patentes, os índices de impacto e o empreendedorismo científico.

Pondera-se que, apesar de as condiçôes de trabalho serem essenciais para garantir o exercício profissional docente, sua precarização é uma tendência nas diversas profissóes, tendo em vista o modelo econômico de exploração do trabalhador pelo capitalismo, adotado em escala mundial. 
Tal fenômeno refere-se à perda de direitos trabalhistas na carreira e/ou às limitações das condiçóes objetivas e subjetivas para o exercício profissional. (RODRIGUES, M., 2002)

Nessa direção, este estudo contou com entrevistas realizadas com gestores acadêmicos e pesquisadores de programas de pós-graduação stricto sensu da UFG pertencentes a três unidades acadêmicas, representativas das áreas de conhecimento de Ciências Exatas e da Terra, Ciências Biológicas e Ciências Humanas. Entendemos que a percepção dos gestores e docentes que atuam especialmente no âmbito da pós-graduação e que lidam mais diretamente com as pressōes e modelaçôes das agências de avaliação e fomento seriam importantes para avançarmos na compreensão das alteraçôes em curso no tocante ao magistério superior.

Seja em âmbito geral, seja no caso da UFG, é possível constatar, no tocante à categoria docente, a ampliação de processos de precarização do trabalho, no que concerne às condiçóes objetivas e subjetivas de desenvolvimento das atividades acadêmicas (SOUZA, 20I3). Tanto o processo de intensificação do trabalho docente quanto as limitaçóes decorrentes da insuficiente infraestrutura materializam a precarização, fato presente em muitas universidades públicas, sobretudo as federais. (MANCEBO; MAUÉS; CHAVES, 2006; MANCEBO; SILVA JÚNIOR, 20I2; SGUISSARDI; SILVA JÚNIOR, 2009)

\section{Os caminhos da investigação sobre o trabalho docente na UFG: a percepção de gestores e professores dos programas de pós-graduação stricto sensu}

Para apreender os elementos constitutivos do processo de precarização das condiçóes do trabalho docente na UFG privilegiamos a dimensão qualitativa por trazer elementos que desvelam a dinamicidade dos processos que envolvem o magistério superior. Muito embora tenha-se assumido o materialismo histórico e dialético como método de investigação, por possibilitar a apreensão do objeto de pesquisa com mais acuidade crítica, dada a abordagem das condiçóes materiais que interferem na organizaçáo e nos processos de trabalho, assinala-se que existem aspectos que escapam às categorias de investigação, tornando a imersão investigativa um 
processo de contínua descoberta. Nessa perspectiva, e durante o processo de imersão teórica e empírica, a abertura para problematizar, criar nexos entre vozes destoantes e lançar questionamentos permitiu um exercício intelectual para a construção de inter-relaçôes entre os dados da pesquis (OLIVEIRA, 200I, p. I9)

Assim, a análise aqui empreendida evidencia aspectos que se mostraram pertinentes à realidade da UFG, locus da pesquisa e instituição que está imersa no sistema de educação superior, sobretudo federal. A universidade possui características e peculiaridades específicas, mas compóe o universo da educação superior, que por sua vez comporta outras instituições tais como faculdades isoladas e centros universitários. A opção pela UFG ocorreu por esta instituição integrar o quadro das universidades públicas federais, que vem passando por modificaçóes acentuadas decorrentes das políticas do governo federal desde a segunda metade dos anos de I990. (OLIVEIRA, 2000)

Foram considerados, ainda, outros dois aspectos: a) ser uma universidade com mais de 50 anos de existência e que vivenciou interferências na sua organização ao longo da história que refletem projetos e demandas que redefinem sua identidade institucional (FERREIRA, 2009; RODRIGUES, 20II); b) congregar, há algumas décadas, professores concursados que vivenciaram a realizaçáo do trabalho docente antes da reforma da educação superior pelas políticas públicas de 1990, a partir do governo Fernando Henrique Cardoso (FHC) (1995-2002).

A primeira etapa da pesquisa consistiu na revisão da literatura e pesquisa documental, com constante atualização das produçóes que versam sobre a temática 'trabalho docente no magistério superior'. A segunda fase foi de incursão empírica no campo universitário, tendo o trabalho docente na UFG como objeto de estudo. Partindo do quadro mais geral da instituição, as unidades acadêmicas elegidas para esta pesquisa correspondem às áreas de polarização no âmbito do campo científico, quais sejam: o Instituto de Física (IF), da área das Ciências Exatas e da Terra, com o curso de Física; o Instituto de Patologia Tropical e Saúde Pública (IPTSP), da área das Ciências Biológicas, com o curso de Parasitologia; e a Faculdade de Educação (FE), da área das Ciências Humanas, com o curso de Pedagogia. 
Foram realizadas entrevistas semiestruturadas com professores da UFG que ocupam cargos na gestáo acadêmica, ou que realizam pesquisas vinculadas à pós-graduação da instituição ${ }^{\mathrm{I}}$. A definição dos sujeitos da pesquisa teve como critério serem doutores em regime de trabalho de dedicação exclusiva (DE). Esclareça-se que ser do quadro efetivo da UFG e do regime de DE foram os principais critérios da seleção dos sujeitos da pesquisa. Tal critério partiu do entendimento de que o professor com esse perfil tem mais condiçóes de se envolver com a instituição, o que favorece uma percepção mais aguçada dos embates, desafios e caminhos do trabalho docente no magistério superior.

Outro critério foi a seleção de professores ${ }^{2}$ mais experientes, que atuam na UFG desde a década de 1990, por se compreender que tinham outro parâmetro de atuação no magistério superior antes da promulgação da LDB (Lei no 9.394/1996), que abriu precedente para uma verdadeira reforma desse nível educacional. Portanto, são professores que têm uma referência do trabalho docente sobre outras bases, que não necessariamente a do produtivismo acadêmico ${ }^{3}$, e que pelas suas experiências trazem elementos para o entendimento de como a regulaçáo do ofício atinge o 'ser professor' na universidade pública federal no contexto atual.

A definição dos sujeitos da pesquisa respeitou a disponibilidade dos professores em colaborarem com o estudo. Foram realizados contatos telefônicos e pessoais, para apresentar a proposta de investigação, e com os professores que aceitaram ser entrevistados foram agendadas as datas. Ao finalizar as entrevistas com os professores experientes e já na fase de transcrição, chamou a atenção a recorrência de relatos sobre a capacidade de professores que ingressaram recentemente na UFG de se adaptarem às mudanças expressivas no contexto da universidade, que segundo eles foram realizadas sobretudo nos anos 2000 .

Por isso, considerou-se pertinente voltar ao campo de pesquisa para entrevistar professores que tiveram sua inserção na UFG no período supracitado. Deve-se considerar que esses professores encontraram a universidade com padrôes já constituídos de produtividade e com exigências de incorporação de mais atividades ao trabalho docente no magistério superior. Tendo em vista essa peculiaridade, as entrevistas foram realizadas conforme aceite dos professores, trazendo contrapontos interessantes para a análise dos dados. 
Ao todo foram realizadas I5 entrevistas, I2 delas com professores experientes e três com professores que ingressaram na UFG nos anos 2000 , estes denominados jovens doutores, pois a maioria deles terminou o doutorado há menos de dez anos. As entrevistas tiveram o áudio devidamente gravado, com tempo de duração média de 40 minutos, guiadas segundo o entendimento de que se trata de uma "conversa intencional, geralmente entre duas pessoas, embora por vezes possa envolver mais pessoas, dirigida por uma delas com o objetivo de obter informaçôes sobre a outra." (MORGAN, I988 apud BOGDAN; BIKLEN, I994, p. I34)

Todos os dados coletados foram analisados na perspectiva da complementaridade de fatos, situaçóes ou posicionamentos que elucidam as novas exigências dirigidas ao trabalho docente. A análise parte do entendimento de que

não restam dúvidas de que as mudanças no sistema de educação superior brasileiro foram profundas, complexas e diferenciadas, conforme o subsetor em análise (IES privadas, federais, estaduais e municipais), e que provocaram fortes impactos no trabalho ali realizado. (MANCEBO; SILVA JÚNIOR, 20I2, p. 2I)

É a partir desse ponto de vista que se discute o trabalho docente na UFG. Para tanto, empreendeu-se, ainda, a análise de conteúdo de entrevistas e de documentos institucionais, em busca de sentidos e interligaçóes de mensagens nas fontes de pesquisa. Para sintetizar a categorização, em especial das entrevistas com os professores da amostra na UFG, fez-se uso do software NVIVO Io.o, específico para tratamento de dados qualitativos, que permite a criação de categorias analíticas e unidades temáticas interligadas, de modo que as informaçóes pudessem ser cruzadas entre categorias, unidades temáticas e por classificações previamente determinadas pelo pesquisador. No caso desta pesquisa, optou-se pelas seguintes classificaçôes: a) unidades acadêmicas; b) inserção na graduação e na pósgraduação; c) professores experientes e jovens doutores.

Desse modo, buscou-se uma abordagem que desvelasse as relaçóes implicadas nos processos que envolvem o professor universitário e as novas exigências para o trabalho docente no magistério superior. 


\section{O trabalho docente no magistério superior em tempos de reconfiguração: sentidos e práticas em (des) construção}

Nos relatos dos gestores acadêmicos e pesquisadores de programas de pós-graduação stricto sensu da UFG observa-se a predominância da precarização das condiçóes subjetivas e objetivas de trabalho. Trata-se de uma precarizaçáo que alude a aspectos que se materializam por meio da subjetividade docente, de modo que atingem o sujeito professor e que, em larga medida, são regulaçôes assimiláveis e que interferem no cotidiano do trabalho docente. Já as condiçóes objetivas de trabalho dizem respeito a questóes estruturais, de ordem material, e que também comprometem o desenvolvimento do trabalho.

Os professores, ao discorrerem sobre as principais dificuldades para realizar o trabalho docente no magistério superior, afirmam, por exemplo, como a burocracia constitui um aspecto que os pressiona no cotidiano: "Mas isso é um problema da universidade como um todo, os processos burocráticos são muitos lentos, isso realmente é uma coisa que desde o primeiro dia que tomei posse me incomoda." (Entrevista I, 20I $5^{4}$ )

É possível observar um aumento das atividades administrativas online, no contexto da educação superior, especialmente nas universidades federais. Pode-se dizer que o excesso de tarefas e atribuiçóes burocráticas retira os professores de uma relação genuína com seu trabalho, conforme evidencia o relato abaixo, que é retomado pela clareza quanto a esse processo.

Enfim, a situação é que você precisa atender uma série de demandas [administrativas, vinculadas à burocratização dos processos] que são de enormidade tremenda, demandas externas e internas, com prazos muito curtos. O grande volume delas é que impedem que você faça o que é inerente ao trabalho de um professor de ensino superior, que é, de um lado, estudos e de outro, efetuar pesquisa. (Entrevista 2, 2015 )

Trata-se de uma reflexão sobre como as exigências relacionadas às atividades administrativas da universidade vão distanciando o professor do 
cerne de seu trabalho. Os professores apontam que as tarefas administrativas e burocráticas aumentaram sobremaneira, e demonstram discordar dessa lógica. Compreende-se que a burocracia é uma atividade-meio na docência, sendo necessária para regular as atividades realizadas; todavia, questiona-se sua função de controle excessivo dos processos, conforme reflete um professor: "Esses sistemas vêm num discurso de aprimorar, de garantir uma integração de informação, mas no fundo ele é muito mais de controle, de controle de trabalho e de gastar tempo, que poderia ser usado para uma produção acadêmica." (Entrevista 3, 2001 $5^{6}$ )

Outro ponto que implica a precarização das condiçóes subjetivas de trabalho é a pressão para a produção acadêmico-científica, materializada na busca de fomentos e na publicação de artigos, como atestam os excertos a seguir. Os docentes questionam tanto a dificuldade de conseguir os fomentos para a realizaçáo de pesquisas quanto os padrốes de qualidade da produção acadêmico-científica. Ao tratar dessa questão, um professor problematiza a base científica dos escores de produtividade e que é muito apropriada ao debate proposto:

De onde é que vem, a partir de que trabalho vem a autorização de um grupo de pesquisa, de um professor, de um pesquisador doutor? [...] O próprio sistema Capes, sistema de publicação de artigos, o modo como eles contam, até mesmo a seleção no serviço público [para magistério superior] o quantitativo ali não permite que você faça uma avaliação do que de fato seja um pesquisador, qual a consistência daquilo que aquele cara pesquisa [...]. A crise é de consistência na formação científica [...]. (Entrevista 4, 201 $5^{7}$ )

Destaca-se que, além de questionar os escores de produtividade estabelecidos pelo padrão de avaliação da Capes, o entrevistado aponta que a produtividade atinge os professores ingressantes ainda nas bancas dos concursos, visto que os processos seletivos ponderam a quantidade de sua produção acadêmico-científica para pontuação de títulos.

Ao abordar especificamente a pesquisa e sua correlaçáo com a inovação, os professores posicionam-se contraditoriamente a esse processo, pois enquanto alguns consideram ser natural tal vinculação, outros são vee- 
mentemente contrários. Alguns dos professores ponderam acerca da importância de se realizar pesquisa como forma de contribuir para a sociedade; outros, por sua vez, posicionam-se contrários ao discurso de inovação e do empreendedorismo, mas há também os que evidenciam uma posição mais alinhada ao empreendedorismo acadêmico.

[E.: Qual a principal dificuldade para realizar seu trabalho?] Eu acho que é a concepção mesmo de pesquisa, sabe? Essa mudança aí mesmo agora na própria Pró-Reitoria de Pesquisa, de vincular pesquisa à inovação, essa coisa que vem das áreas técnicas, isso é um complicador. (Entrevista 4, 2015)

Quem vai ser o professor de 2020? Ele vai ser o professor, que se a gente mudou nossa realidade da sala de aula, de começar a dizer que os alunos têm que também trabalhar na iniciativa privada, porque quando eles virarem doutores a gente náo vai ter vaga para eles no ensino superior, a gente começa a criar um grupo de docentes em 2020 que são docentes que vão querer dar aula, porque é prestígio, porque é importante ser pesquisador e porque ali gera conhecimento, são os três princípios que traria a pessoa. Mas ele vai sentir que ele tem que trabalhar fora. Aí, a gente tem de orquestrar isso agora, porque senão ele vai fazer bico, ao invés de fazer uma coisa que seja empreendedora dentro da carreira dele. Por exemplo, um engenheiro que vai abrir uma cervejaria, isso é bico, ele vai fazer uma coisa que talvez seja o hobby dele, mas não tem nada a ver com a profissão dele. $\mathrm{O}$ que a gente precisa de 2015 a 2020, para pegar essas pessoas que vão trabalhar na universidade, é conseguir aumentar o ensino de empreendedorismo e inovação dentro da pós-graduação, já que na graduação está engatinhando. A gente precisa acelerar esse processo. Por quê? Eles vão ser pessoas que vão sentir que não vão poder ter $\mathrm{DE}$, e a gente precisa canalizar isso, não a condição de $\mathrm{DE}$ para o que o Brasil precisa agora, que é patente, transferência de tecnologias e trabalhar na iniciativa privada. (Entrevista $5,2015^{8}$ ) 
Ao se analisar as entrevistas de oito professores, dos cursos de Parasitologia e Física, observa-se que consideram natural vincular pesquisa à inovação e ao empreendedorismo, atestando a característica dessas áreas de produtoras de tecnologias. Já os seis professores entrevistados, vinculados ao curso de Pedagogia, questionam o viés inovador das pesquisas e a delimitação das temáticas. Nesse contexto, Mancebo e Silva Júnior (20I2) entendem que as consequências dessa perspectiva são as mudanças ocorridas na cultura acadêmica, que acabam conformando princípios da produção mercadológica dentro da universidade pública.

Compreende-se que a pesquisa, conforme afirma Bosi (2007), deva estar vinculada ao campo de estudo do docente, e náo necessariamente atender a editais de fomento na delimitação das temáticas. Tal perspectiva, pontua o autor, pode inviabilizar a produçáo intelectual nas mais diversas linhas de pensamento. Ressalte-se ainda que a definição das temáticas a serem pesquisadas pelas agências de fomento promove uma cisão entre concepção e execução do trabalho docente no âmbito da pesquisa, o que aponta para as bases da gerência científica ${ }^{9}$ no cotidiano da universidade pública, nos moldes explicitados por Braverman (1987).

Ao problematizar a delimitação de temáticas de pesquisa a partir dos editais de fomento, um professor entrevistado acaba revelando que os recursos para a pesquisa acadêmico-científica são limitados:

Qual que é o abismo? O abismo é essa produtividade maluca, o abismo é a falta de recursos, os recursos limitados, sem muito se estabelecer que critérios [...] a quem ele vai se destinar, portanto, diante do abismo, salve-se quem puder, e aí as pessoas se juntam em feudos pra defender as migalhas que são atiradas por aí. (Entrevista $6,2015^{10}$ )

Apesar do tom metafórico, o relato do professor retrata a disputa entre seus pares por fomento para a manutenção de suas pesquisas. Ressalta também a constituição de feudos ou grupos de pesquisa organizados para garantir a sobrevivência no meio acadêmico, no sentindo de atender aos escores de produtividade.

A análise das entrevistas revela que os professores, ao tecerem críticas à produtividade estabelecida pela Capes, acabam explicitando como 
essa lógica interfere na relação de autocriação do profissional com seu trabalho. Por isso, há o estranhamento dos professores com o trabalho que realizam, o que "até bem pouco tempo sequer era visto como tal." (SGUISSARDI, 20I2, p. I3) Trata-se de um trabalho vinculado ao campo produtivo em que a pesquisa, na perspectiva da inovação, desestabiliza a autonomia docente do magistério superior e remodela as identidades docentes dos professores universitários (LAWN, 200I). Pondera-se, ainda, que a lógica do produtivismo não se circunscreve à UFG, tratando-se antes de uma política nacional, conforme o relato de um professor: "Isso é política nacional, tem modificado a forma das pessoas pensarem, e eu acho que isso tem limitado, em muitos casos, o desenvolvimento de novas pesquisas [...]. Eles usam esse termo aqui, "publique ou morra", morra cientificamente. (Entrevista 7, 201 ${ }^{\mathrm{II}}$ )

A percepção de um movimento de mudança de pensamento estende-se às alteraçóes de comportamento dos professores, que acabam se submetendo às exigências da produtividade para garantir a continuidade de recursos para suas pesquisas e garantir a sobrevivência acadêmica (SGUISSARDI, 20Io). Por isso, os processos que envolvem o fazer acadêmico, que atualmente é regulado pela avaliação das agências de fomento e pelos sistemas informatizados da universidade, têm influenciado a construção de uma sociabilidade produtiva na universidade pública, que é calcada nas relaçóes e trocas simbólicas entre os agentes do campo universitário com vistas à manutenção dos escores de produtividade.

Diante do exposto sobre a precarização subjetiva das condiçóes de trabalho, as novas atribuições do professor universitário são consideradas excessivas e, por essa razão, o ritmo do trabalho é acelerado para que dê conta de atender a mais demandas, vinculadas, em especial, ao controle do fazer acadêmico, na perspectiva de inseri-lo no campo econômico-produtivo. É importante pontuar que subjaz a esse tipo de precarização outro fenômeno: a autocoação, ou auto-intensificação, que consiste em uma dedicação intensa do trabalhador ao seu ofício, mesmo quando as regras determinadas externamente abalem sua profissão (HELOANI, 20I I). No campo universitário, esse fenômeno tem se mostrado com mais nitidez, quando se observa professores da pós-graduação que extrapolam o tempo e o espaço do trabalho buscando atender às exigências das agências de 
fomento, comprometendo, inclusive, sua saúde, como relata um professor entrevistado:

Eu gosto muito do que eu faço, eu não adoeci, ainda não. É assim, existe um estresse próprio ali próximo a setembro, outubro e novembro, crise de dor na coluna... um tempo mais intenso que eu estava sem licença, uma certa disritmia, mas eu tenho que parar e fazer meu pilates, e ao mesmo tempo, nessa hora, eu passo a dizer não, mas eu podia estar dizendo não há mais tempo, entendeu!? [...] eu mesmo dei o ritmo. (Entrevista 4, 2015)

Observa-se a culpabilização pelo ritmo de trabalho exaustivo no relato acima, sendo justificado por um gosto pelo trabalho. No entanto, cabe a ressalva de que a negativa em se envolver nas atividades do campo universitário, em larga medida, desdobra-se em exclusão de processos e possíveis fomentos.

Compreende-se que a dedicação dos professores colaboradores desta pesquisa às diversas atividades que lhes são atribuídas desdobra-se na precarização subjetiva das condiçóes de trabalho e podem estar sendo forjadas por meio de sofisticados sistemas simbólicos de apreensão das subjetividades docentes, como nos mostra Heloani (20II) em seus estudos. Tal sistema ganha materialidade no campo produtivo ao substituir as ordens por regras, de modo a enaltecer os valores de determinada empresa expressos no discurso de 'missão'. Partindo desse princípio, flexibilizam-se os caminhos para atingir metas de produtividade, reorganizando os trabalhadores em grupos de trabalho, no caso dos professores universitários, em comissões de trabalho, envolvendo-os em uma simbiose de responsabilização pela produtividade. (HELOANI, 20II)

Outra forma de precarização do trabalho refere-se às condições objetivas, concernentes às questôes estruturais em que obras, infraestrutura e limitação de laboratórios e aparelhos tecnológicos são citados. No caso específico da infraestrutura física da UFG, os relatos sobre obras inacabadas referem-se à unidade de Física, que vivencia a peculiaridade de uma reforma não concluída do prédio que vai abrigar mais laboratórios, iniciada com recursos do Reuni ${ }^{22}$. 
Nosso problema aqui era de espaço físico, porque nós conseguimos equipamentos, mas não tínhamos onde montar o laboratório com infraestrutura legal. Bom, não tinha? Tinha, mas demorava um pouco talvez pra conseguir fazer esse acerto e tal. A gente está com um prédio aqui do lado para ser reformado já tem uns dois anos, e as coisas chegaram para ser instaladas, e lá não tá pronto e a gente está tendo que se virar aqui de maneira precária. (Entrevista 7, 2015)

Nós tínhamos o prédio da Física, aquele prédio da Matemática agora ele é nosso [...] tanto que já tem laboratórios funcionando lá. O problema é que ele tá daquele jeito, porque a firma que ganhou a licitação para reformar o prédio faliu, tem todos os problemas burocráticos. (Entrevista professor $8,2015^{13}$ )

Trata-se de uma situação muito específica, se pensada a UFG como um todo, em que se observa uma ampliação física de 90\% desde o Reuni. Ao todo, 66 novas dependências físicas, entre laboratórios, bibliotecas e prédios, foram construídas, e, destas, 60,6\% foram financiadas com recursos desse programa. Foram reformados também 54 prédios, dos quais

Há coisas na UFG que poderiam ser melhor, por exemplo, o cuidado com a infraestrutura, com os professores. Então, a gente vê que as coisas que a gente consegue para ter uma melhor qualidade de trabalho, eu consegui com meu esforço. A cadeira em que estou sentada, eu comprei com meu dinheiro pessoal, porque eu precisava de uma cadeira mais confortável pra trabalhar; o computador que eu trabalho, eu consegui através do fomento do $\mathrm{CNPq}$, mas porque eu fui atrás e consegui o financiamento, e dentro do dinheiro eu previ comprar esse computador, porque a universidade me deu uma mesa para eu 
trabalhar, e uma cadeira ruim [...]. A infraestrutura poderia ser melhor. (Entrevista 7, 2015)

Tal posicionamento de busca por fomentos para garantir condiçôes de trabalho é recorrente nas universidades federais e incorre na responsabilização do professor por aspectos que dizem respeito à instituição (MANCEBO; MAUÉS; CHAVES, 2006; SGUISSARDI; SILVA JÚNIOR, 2009). Ao ponderar sobre a condições de trabalho, um professor experiente considera que há certo descaso da unidade na qual trabalha para garanti-las:

O descaso mesmo com as questôes estruturais, estrutura física, estrutura tecnológica, elas são muitos precárias, as condições de trabalho são muito precárias. Existem unidades que já priorizaram isso, que hoje os gabinetes dos professores têm mínimas condiçóes para o professor ficar lá um período todo, estudando trabalhando, mas na $\mathrm{x}$ [diz o nome de sua unidade] isso nunca foi prioridade e está cada vez pior. Eu não trabalho lá há muito tempo; eu tenho uma sala com meu nome, um computador que já tem mais de dois anos que náo liga porque falta uma extensão e eu me nego a comprar a extensão porque eu acho que isso é uma obrigação da instituição. Sem falar na manutenção dos computadores, que muitas vezes estáo sucateados. [...] falta segurança também, há vários fatos que já ocorreram nesse sentido. (Entrevista 3, 2015)

Apesar de esses dois professores detalharem os limites observados nas condiçóes estruturais de trabalho, explicitando o descontentamento que sentem para realizar suas atividades diante de tal realidade, os demais posicionamentos sobre essa situação são díspares. Contudo, chama a atenção a pouca menção às condiçóes objetivas de trabalho entre os entrevistados, o que náo corrobora parte importante da literatura da área. Isso talvez possa ser específico do caso da UFG ou ainda do fato de o professor se sentir cada vez mais responsável por adquirir os equipamentos e melhorar o espaço físico em que trabalha. 
Ao discorrerem sobre as atuais de condiçôes de trabalho, três professores experientes ressaltam que, na UFG, elas eram bem mais precárias na década de I990. Destaca-se a fala de um deles:

A situação na época [199I] era de falta de equipamentos, falta de verba, uma época muito difícil. A gente não tinha nada, nossos laboratórios, os equipamentos de pesquisa não atendiam às minhas necessidades. A gente tentava aqui, tentava ali, comprava um equipamento, comprava outro, mas nada andava, a gente não conseguia ter qualidade na pesquisa. Se eu quisesse fazer pesquisa, eu tinha de sair de Goiânia (...). Também naquela época não existia muitas expectativas de a gente sair e fazer pesquisa fora. (Entrevista 8, 2015)

Ao se referir às questóes salariais, um professor assevera: “Teve uma fase brava de oito anos, foi brava, que a gente não teve aumento nenhum. [E.: Foi a época do FHC?] Foi, foi uma fase muito brava." (Entrevista 9, $\left.2015^{14}\right)$ Trata-se de relatos sobre um momento histórico de sucateamento das universidades federais, com diminutos recursos do Tesouro para sua manutenção, bem como de congelamento de salários e suspensão de concursos públicos. Por isso, é lembrada como

uma época muito dura, muito difícil, de desmantelamento da universidade, de achincalhamento com a gente que era professor. Por exemplo, a gente às vezes tinha vergonha de dizer que era da universidade federal, porque eram editoriais esculhambando a gente e desmerecendo. (Entrevista 8, 2015)

Ainda sobre a precarização das condiçóes objetivas de trabalho, dois professores consideram que elas melhoraram, se analisados a disponibilidade de fomentos externos em I990, que eram raros, e o limitado acesso às produções científicas.

Houve a compreensão melhor dos órgãos de fomento, como $\mathrm{CNPq}$, Capes, com programas específicos. Esses programas 
específicos, para mim, nasceram financeiramente da Carta de Salvador de 2004, quando se falou que, se alguém colocar dinheiro, a gente coloca. Isso melhorou muito o cenário, muito as condiçôes de trabalho. (Entrevista 5, 2015)

Meu trabalho mudou muito, a principal mudança foi o Portal da Capes e os fomentos [...] No começo, eu tinha de ficar o dia todo na UnB para ter acesso à bibliografia. Eu ia ler um artigo, ia ver uma referência, tinha que voltar para Brasília [...] A melhor coisa na minha vida acadêmica foi o portal da Capes. ( Entrevista IO, 2015 ${ }^{15}$ )

Mais uma vez as condições objetivas de trabalho são relacionadas aos fomentos, demonstrando a naturalização dessa vinculação. No que concerne à perspectiva de melhorias das condiçóes de trabalho, um professor reflete sobre a conjuntura nacional de 2015 e aponta uma tendência de piora do quadro:

A gente está passando agora por uma crise geral, e essa crise chegou aqui. A universidade teve cortes 30\% numa rubrica, $47 \%$ na outra, parece que não vai ter dinheiro para pagar energia, limpeza e tal. Bom, isso é um lado, o da pesquisa também faltou. Os pesquisadores estavam acostumados a fazer os projetos, ganhar o dinheiro para montar os laboratórios e ter dinheiro para manter aquilo em funcionamento, e parece que a partir deste ano, tudo indica que as dificuldades virão. (Entrevista 7, 2015)

Ao analisar o atual contexto de retração de investimentos nas universidades federais, o relato acima demonstra lucidez quanto às dificuldades a serem enfrentadas em tempos de consolidação de um modelo educacional economicista.

De modo geral, as reflexóes empreendidas sobre o trabalho docente na UFG indicam que a precarização das condiçôes de trabalho docente, em especial, as relativas às condições subjetivas, desdobram-se na autocoação docente, fenômeno predominante entre os sujeitos da pesquisa. É 
visível, pois, que o trabalho docente na UFG, em tempos de mudanças significativas na educação superior, vem sendo modificado, o que pode ser percebido nos novos sentidos e práticas em (des)construção.

\section{Consideraçóes Finais}

$\mathrm{Na}$ análise aqui empreendida sobre o trabalho docente na UFG observaram-se processos concretos de flexibilização, intensificação e precarização, considerando as políticas de educaçáo superior, as demandas econômico-produtivas e as próprias exigências do campo científico. Nesse sentido, verificou-se a aceleração e intensificação do ritmo de trabalho, contaminando inclusive a vida pessoal dos professores, o que tem resultado em problemas de saúde e ampliação do mal estar docente. É possível perceber, também, que há um aumento das tarefas atribuídas aos docentes, em especial as administrativas ou burocráticas, que estão reguladas por sistemas informatizados da universidade; tais sistemas requerem cada vez mais dispêndio de tempo, o que tem distanciando os professores das atividades tradicionais do magistério superior - o ensino, a pesquisa e a extensão. Há relatos recorrentes de que o acesso a esses sistemas informatizados ocorre em casa, sobretudo de noite ou nos fins de semana, tornando indissociável o tempo de trabalho e o tempo privado dedicado ao descanso e lazer.

As exigências para o aumento da produtividade acadêmica mostrase como outro gargalo presente no cotidiano do trabalho no magistério superior. A demanda por alta produção acadêmico-científica, atendendo à regulação da Capes, CNPq e outras agências de fomento, assim como aos periódicos científicos mais bem classificados, é uma realidade consolidada no campo científico, instaurando um modelo de avaliação que pressiona os professores a supervalorizarem a produção científica, especialmente em termos de artigos, índices de impacto e registros de patente.

Nesse contexto, cabe ponderar que o campo universitário, com seu habitus ou modus operandi, ressignifica as exigências atribuidas a ele por meio da construção de microrregulaçôes, ou seja, as regulaçôes são sempre ressignificadas ou alteradas, produzindo novas regulaçóes (BARROSO, 2006). Isso quer dizer que exigências do campo econômico-produtivo, como a de produção tecnológica e inovaçôes, só são assimiladas na 
educação superior porque encontram acolhida no campo universitário. Compreende-se que, nessa direção, se instalou o produtivismo acadêmico nas universidade federais, amplamente identificado nos relatos dos professores entrevistados e na literatura examinada.

No que concerne à precarização subjetiva, que foi reiteradamente citada nas entrevistas realizadas, compreende-se que em alguma medida os professores apontam terem assumido a intensificação de suas atividades, em especial as administrativas e de pesquisa, em prol da expansão da UFG. Destaca-se ainda que, por um lado, os professores visualizam melhorias em relação aos desinvestimentos da década de 1990 e se empenharam para aproveitar as oportunidades de investimento na pesquisa; por outro, o Estado busca atribuir à universidade o papel de instituição estratégica para potencializar a acumulação de capital, dada a ênfase na pesquisa inovadora, que traz sérias consequências ao trabalho do professor universitário. (MANCEBO; SILVA JÚNIOR, 20I2)

A análise empreendida possibilita, pois, pontuar que as dificuldades e desafios interpostos ao professor universitário em tempos de forte regulação, controladora do trabalho docente, busca alinhar suas práticas ao atendimento das demandas econômico-produtivas, mas também às exigencias do campo científico cada vez mais internacionalizado. $O$ fato inexorável é que estão ocorrendo alteraçóes na natureza e no caráter do trabalho docente, decorrentes, em grande parte, de demandas externas, o que tem ampliado a heteronomia na produção, organização, gestão e finalidades da universidade.

\section{Notas}

I O recorte empreendido foi observado após a seleção dos professores a serem entrevistados e explicita a polarização das atividades realizadas pelos docentes, trazendo assim elementos diversos que enriquecem o debate proposto.

2 Utiliza-se o termo professores para se referir aos gestores acadêmicos e pesquisadores da pósgraduação, por se considerar que a condição de docente é comum aos grupos pesquisados, mesmo que desempenhem atividades diferentes no campo universitário.

3 O produtivismo acadêmico é um fenômeno que tem instaurando novas bases para a produção acadêmico-científica, tendo em vista as exigências de produtividade das agências de avaliação e fomento. Essas produções são submetidas ao crivo do modelo Capes de avaliação, ou mesmo ao CNPq, instituído com nitidez a partir de 1997/I998. (SGUISSARDI; SILVA JÚNIOR, 2009)

4 Todas as entrevistas foram realizadas com gestores e pesquisadores da UFG e concedidas para a tese de doutorado: Políticas para Educação Superior e suas implicações no trabalho, profissão e 
profissionalização docente em unidades acadêmicas da Universidade Federal de Goiás (UFG). As entrevistas estão enumeradas conforme sua realização. Entrevista I, Instituto de Patologia e Saúde Pública. Entrevistadora: PAZ, S.L.: UFG, 2015.

5 Entrevistado professor 2, Faculdade de Educação [março 2015].

6 Entrevistado professor 3, Faculdade de Educação [março 2015].

7 Entrevistado professor 4, Faculdade de Educação [março 2015].

8 Entrevistado professor 5, Instituto de Patologia e Saúde Pública [março 20I5].

9 Taylor (apud BRAVERMAN, 1987) sistematiza a gerência científica combinando técnicas de controle, ritmo acelerado e parcelamento do trabalho, em uma alusão à incorporação da ciência aos métodos de gerência.

Io Entrevistado professor 6, Faculdade de Educação [março 2015].

II Entrevistado professor 7, Instituto de Física [março 20I5].

I 2 Programa de Apoio a Planos de Reestruturação das Universidades Federais (Reuni) foi lançado em 2007 para promover a ampliaçáo do acesso nas universidades federais em todo o Brasil. Todas as universidades federais aderiram ao Programa e promoveram uma ampla expansão dos cursos de graduação.

I3 Entrevistado professor 8, Instituto de Física [março 20I5].

I4 Entrevistado professor 9, Instituto de Patologia e Saúde Pública [março 20I5].

Is Entrevistado professor Io, Instituto de Patologia e Saúde Pública [março 20I5].

\section{Referências}

BARROSO, João. O Estado e a Educação: a regulação transnacional, a regulação . (Org.) A Regulação das políticas públicas de educação: Espaços, dinâmicas e actores. Lisboa: Imprensa de Coimbra Ltda., 2006. p. 4I-70.

BOGDAN, Robert; BIKLEN, Sari. Investigação qualitativa em educação - uma introdução à teoria e aos métodos. Porto: Porto Editora, 1994.

BOITO JÚNIOR, Armando. Política neoliberal e sindicalismo no Brasil. São Paulo: Xamã, 1999.

BOSI, Antonio de Pádua. A precarização do trabalho docente nas instituiçóes de ensino superior do Brasil nesses últimos 25 anos. Educação \& Sociedade. Campinas, SP, v. 28, n. IOI, p. I503-I523, set./dez. 2007.

BRAVERMAN, Harry. Trabalho e capital monopolista: a degradação do trabalho no século XX. Trad. Nathael C. Caixeiro. 3. ed. Rio de Janeiro: Guanabara, 1987.

FERREIRA, Suely. A universidade do século XXI: concepçôes, finalidades e contradiçóes. 2009. 305f. Tese (Doutorado em Educação) - Faculdade de Educação, Universidade Federal de Goiás. Goiânia, 2009.

HARVEY, David. Condição pós-moderna. 23 ed. São Paulo: Loyola, 2012. 
HELOANI, Roberto. Gestão e organização no capitalismo globalizado. São Paulo: Atlas, 2 OII.

LAWN, Martin. Os professores e a fabricação de identidades. Currículo sem Fronteiras. São Paulo, v. I, n. 2, p. II7-I30, jul./dez. 200 I.

MANCEBO, Deise; MAUÉS, Olgaíses; CHAVES, Vera Lúcia Jacob. Crise e reforma do Estado e da Universidade Brasileira: implicação para o trabalho docente. Educar em Revista. Curitiba, n. 28, p. 37-53, 2006.

MANCEBO, Deise; SILVA JÚNIOR, João dos Reis. Apresentação. In:

. Trabalho docente e expansão da educação superior. Rio de Janeiro: EdUERJ,

2012. p. 19-26.

MAUÉS, Olgaíses. A reconfiguração do trabalho docente na educação superior. Educar em Revista, Curitiba, n. I, ed. Especial, p. I4I-I60, 20 IO.

OLIVEIRA, João F. A reestruturação da educação superior no Brasil e o processo de metamorfose das universidades federais: o caso da Universidade Federal de Goiás. 2000. ı 9 of. Tese (Doutorado) - Faculdade de Educação da Universidade de São Paulo, São Paulo, 2000.

OLIVEIRA, Paulo de Salles. Caminhos de construção da pesquisa em ciências humanas. In: . (Org.). Metodologia das ciências humanas. São Paulo: Hucited, 2001.

RODRIGUES, Anegleyce Teodoro. A universidade como instituição social de formação $e$ como organização administrada: confronto de sentidos nas reformas acadêmicas do ensino de graduação da Universidade Federal de Goiás entre 1983 e 2002. 201 I. I54f. Tese (Doutorado em Educação) - Faculdade de Educação, Universidade Federal de Goiás. Goiânia, 20II.

RODRIGUES, Maria de Lurdes. Sociologia das profissóes. Oeiras (Portugal): Celta Editora, 2002.

SGUISSARDI, Valdemar. Prefácio. In: MANCEBO, Deise; SILVA JÚNIOR, João dos Reis. Apresentação. In: Trabalho docente e expansão da educação superior. Rio de Janeiro: EdUERJ, 2012. p. I9-26.

SGUISSARDI, Valdemar. Produtivismo acadêmico. In: OLIVEIRA, Dalila Andrade de; DUARTE, Adriana Maria Cancella; VIEIRA, Lívia Maria. DICIONÁRIO: trabalho, profissão e condição docente. Belo Horizonte: UFMG/Faculdade de Educação, 20I0. (CD-ROM).

SGUISSARDI, Valdemar; SILVA JÚNIOR, João dos Reis. Trabalho intensificado nas federais pós-graduação e produtivismo acadêmico. São Paulo: Xamã, 2009. 
SOUZA, Aparecida Neri de. Professores, modernização e precarização. In: ANTUNES, Ricardo (Org.). Riqueza e miséria do trabalho no Brasil II. São Paulo: Boitempo, 2013.

UFG. Universidade Federal de Goiás. UFG 2006 - 2013. Goiânia: Editora UFG, 2013.

Recebido em 29 set. 2017 / Aprovado em 17 jan. 2018 Para referenciar este texto

PAZ, S. L.; OLIVEIRA, J. F. O trabalho docente no magistério superior em tempos de crise e de reconfiguração. EccoS - Revista Científica, São Paulo, n. 46, p. I09-I30. mai./ago. 20I8. Disponível em: <https://doi.org/I0.5585/EccoS.n46.7894>. 